\title{
Obstetric Trainees' Experience in Vaginal Breech Delivery
}

Implications for Future Practice

\author{
Marian Chinnock, MBBS, and Stephen Robson, MM, MPH
}

OBJECTIVE: To determine whether trainee obstetricians intend to offer vaginal breech delivery once they become certified as specialists and to quantify their experience in vaginal breech delivery.

METHODS: This was an anonymous postal survey of all Australian trainee obstetricians. The survey inquired about experience with, confidence in, and intentions regarding planned vaginal breech delivery after trainees' certification as specialists.

RESULTS: Surveys were sent to all 303 Australian registered trainee obstetricians. The response rate was $65 \%$. Experience in vaginal breech delivery increased with year of training, from a median of one delivery for first-year trainees to a median of 12 deliveries for final-year trainees. Although $53 \%$ of final-year trainees reported feeling confident with vaginal breech delivery, only $11 \%$ reported an intention to offer planned vaginal breech delivery at term as a specialist.

CONCLUSION: Few of the next generation of specialist obstetricians plan to offer vaginal breech delivery to their patients.

(Obstet Gynecol 2007;110:900-3)

LEVEL OF EVIDENCE: II

$\mathrm{D}$ uring 2003 in Australia, 4.5\% of fetuses were in breech presentation when born, yet only $0.4 \%$ of all births were vaginal breech deliveries. ${ }^{1}$ The rate of

From the Department of Obstetrics and Gynaecology, Medical School, Australian National University, Canberra, Australia.

The authors thank Professor Keith Dear for his work on the statistical aspects of this article.

Corresponding author: Stephen Robson, Department of Obstetrics and Gynaecology, the Canberra Hospital, PO Box 11, Woden ACT 2606 Australia; e-mail: Steve.robson@act.gov.au.

Financial Disclosure

The authors have no potential conflicts of interest to disclose.

(C) 2007 by The American College of Obstetricians and Gynecologists. Published by Lippincott Williams \& Wilkins.

ISSN: 0029-7844/07 vaginal breech delivery in Australia fell by $60 \%$ over the last decade, and in this respect Australia is representative of many developed nations. One study from the United States found that as few as 5\% of women with breech presentation at term had a vaginal delivery in the period 1991-1999. ${ }^{2}$ Recent declines in the rate of vaginal breech delivery have been linked to publication of the Term Breech Trial that reported the level of neonatal risk as higher in planned vaginal breech delivery than in planned caesarean delivery. ${ }^{3}$ Although there have been a number of critiques of the original conclusions drawn from the Term Breech Trial, ${ }^{4-6}$ obstetric bodies in the United States, ${ }^{7}$ Great Britain, ${ }^{8}$ and Australia ${ }^{9}$ have all published statements that generally endorse that study's original recommendations. Those Colleges' statements make it clear that planned caesarean delivery is usually preferable for term breech delivery, but that cases should be managed according to individual circumstances and with informed consent.

Some authors have called for withdrawal of the original recommendations of the Term Breech Trial, ${ }^{10}$ but such a widespread reversal of management practices would be dependent on many factors. One obvious and important factor influencing the rate of vaginal breech delivery is "availability of an experienced accoucheur." ${ }^{9}$ Trainees in the specialty of obstetrics have reported limited experience in vaginal breech delivery for a number of years, a trend predating publication of the Term Breech Trial. For example, a study of Australian and English obstetric trainees' experience during the period 1992-1996 reported that some were exposed to as few as seven vaginal breech deliveries during their entire training. ${ }^{11}$ A survey of 319 trainees from the United Kingdom in 1994 found that $40 \%$ had performed fewer than 20 vaginal breech deliveries, and only $37 \%$ felt that they had adequate training. ${ }^{12}$ Similar findings have been reported from other countries in Europe 
and North America. ${ }^{13,14}$ No matter what the evidence shows, abandonment of the recommendations of the Term Breech Trial and widespread resurgence in vaginal breech delivery would depend upon enthusiasm from the new generation of obstetricians. To evaluate this, we have undertaken a survey of Australian trainee obstetricians to investigate their levels of experience with vaginal breech delivery and their intentions for practice once certified as specialists.

\section{MATERIALS AND METHODS}

A one-page survey was developed to assess obstetric trainees' levels of experience in, and confidence with, vaginal breech delivery. The survey asked respondents to identify their current training level (Australia has a 6-year training program), as well as their intention to practice obstetrics once certified as a specialist. To reduce the chance of creating "demand characteristics" that might influence respondents' replies, the survey instrument inquired about trainees' experience under the general heading "complex vaginal delivery" with other questions about forceps and rotational deliveries. Three questions relating to experience with vaginal breech delivery were posed:

1. How many vaginal breech deliveries (either singleton, or as part of a vaginal twin delivery) have you personally performed during your training to date?

2. Do you feel that you have received sufficient training and experience to confidently manage vaginal breech birth? (yes, no, or not yet).

3 . In your future specialist practice, would you intend to manage planned trials of vaginal delivery in known term breech presentation? (yes, no, or not sure).
An invitation for written comments was included at the end. The survey form was included with a covering letter detailing the background to and intentions of the study, with a prepaid return envelope. The survey was anonymous and nonresponders could not be identified. Response data were entered into Stata 6.0 (StataCorp, College Station, TX) for analysis. All confidence intervals (CIs) are 95\% intervals, and CIs for proportions were determined by exact binomial calculations. The study protocol was approved by the Human Research Ethics Committee of the Australian National University and was approved for distribution to trainees by the Continuing Professional Development Committee of the Royal Australian and New Zealand College of Obstetricians and Gynaecologists (RANZCOG).

\section{RESULTS}

Survey forms were posted to all 303 registered Australian trainees from July to August of 2006. A reminder e-mail was sent 3 months after initial distribution. A total of 197 replies were received by March 6,2007 , a response rate of $65 \%$. One hundred seventynine respondents $(91 \%, 95 \%$ CI $86-94 \%)$ reported an intention to practice obstetrics once they received specialist certification. Response bias is always a potential issue with any survey of this nature, but the sampling proportions (75\% of first-year trainees, $63 \%$ of second years, $55 \%$ of third years, $62 \%$ of fourth years, $72 \%$ of fifth years, and $73 \%$ of final years) suggest that the surveys are representative.

As expected, the mean and median numbers of vaginal breech deliveries personally performed by respondents increased with each year of training, ranging from a median of one delivery (mean 1.5, $95 \%$ CI $0.6-2.3$ ) for first-year trainees to a median of

Table 1. Number of Vaginal Breech Deliveries Personally Performed by Respondents During Their Training to Date and the Proportions Expressing "Confidence" in Managing Vaginal Breech Deliveries

\begin{tabular}{|c|c|c|c|c|c|c|}
\hline & \multicolumn{6}{|c|}{ Year of Training } \\
\hline & 1 & 2 & 3 & 4 & 5 & 6 \\
\hline Respondents (n) & 42 & 39 & $35^{*}$ & 38 & 23 & 19 \\
\hline $\begin{array}{l}\text { VBDs performed } \\
\text { [range (median)] }\end{array}$ & $0-20(1)$ & $0-20(2)$ & $0-25^{*}(4)$ & $2-50(5)$ & $1-50(10)$ & $3-30(12)$ \\
\hline $\begin{array}{l}\text { VBDs reported } \\
{[\text { mean }(95 \% \mathrm{CI})]}\end{array}$ & $1.9(0.6-2.3)$ & $2.8(1.5-4.1)$ & $6.1 *(4.2-8.1)$ & $7.2(4.6-9.9)$ & $11.3(6.9-15.7)$ & $14.6(10.9-18.4)$ \\
\hline $\begin{array}{l}\text { Respondents reporting } \\
\text { "confidence" in performing } \\
\text { VBD [\% }(95 \% \mathrm{CI})]\end{array}$ & $14(5-29)$ & $8(2-21)$ & $8(2-22)$ & $16(6-31)$ & $48(27-69)$ & $53(29-76)$ \\
\hline
\end{tabular}

VBD, vaginal breech delivery; CI, confidence interval.

* One trainee had undertaken 250 vaginal breech deliveries overseas, excluded from this analysis. 
12 deliveries (mean 14.6, 95\% CI 10.9-18.4) for final-year trainees (Table 1). However, $43 \%$ of firstyear respondents reported never having performed a vaginal breech delivery (18/42, 95\% CI 28-59\%). By their fourth year of training, all respondents had performed at least one vaginal breech delivery.

The proportion of respondents who answered "yes" to the question, "Do you feel that you have received sufficient training and experience to confidently manage vaginal breech birth?" increased by year of training (Table 1). However, 37\% of respondents in their final year of training ( 7 of $19,95 \%$ CI $16-62 \%)$ answered "no" to the question, and another $11 \%$ responded "not yet" (2 of 19, 95\% CI 1-33\%). The 10 respondents who reported that they were confident to manage a trial of vaginal breech delivery had personally performed between three and 30 vaginal breech deliveries during their training (mean 18.1, 95\% CI 12-24).

In response to the question, "In your future consultant practice, would you intend to manage planned trials of vaginal delivery in known term breech presentation?" the proportion of respondents who answered "no" increased significantly with increasing year of training $(P=.001$, logistic regression; Fig. 1). Although the proportion of respondents who answered "yes" decreased, this trend was not significant $(P=.40)$. However, only $11 \%$ of respondents in their final year answered "yes" (2 of 19, 95\% CI $1-33 \%)$. Across all years of training, only $31 \%$ of those who reported being "confident" with vaginal breech delivery reported an intention to manage trials of vaginal breech delivery as specialists (12 of 39, 95\% CI 17-48\%). Of those who were "not confident," only

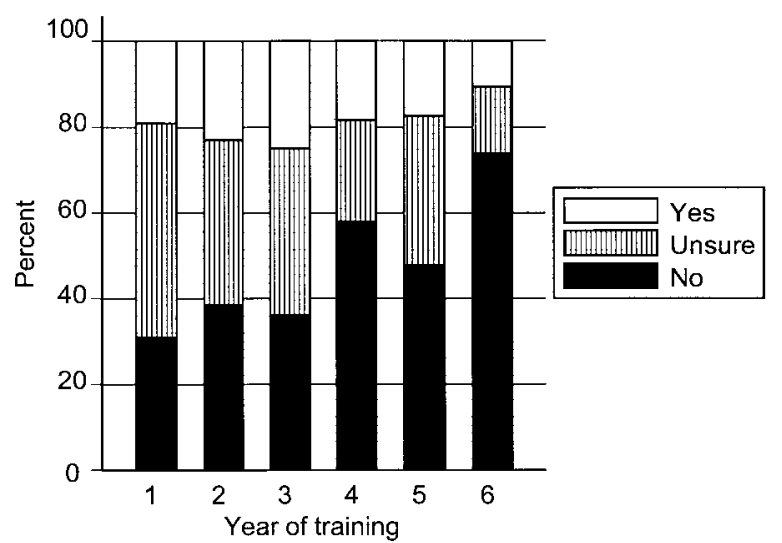

Fig. 1. Responses to the question "In your future consultant practice, would you intend to manage planned trials of vaginal delivery in known term breech presentation?"

Chinnock. Obstetrician Training in Breech Delivery. Obstet Gynecol 2007.
$9 \%$ declared this intention (7 of $77,95 \%$ CI $4-18 \%$ ), whereas for those who were "not sure," the proportion was $25 \%(20 / 81,95 \%$ CI $16-36 \%)$.

\section{DISCUSSION}

This study suggests that only a small proportion of Australian obstetric trainees, when they are in specialist practice, intend to offer their patients planned vaginal breech delivery. During their training, they receive little opportunity to undertake vaginal breech delivery, and by the end of 6 years of training, only $53 \%$ of respondents reported feeling confident to manage vaginal breech delivery. Of special note, the closer to specialist qualification the respondents were, the less likely they were to intend offering planned trials of vaginal breech delivery to women in their care. An individual's level of confidence in undertaking a procedure does not necessarily correlate with competence, and even for experienced obstetricians, regular exposure is necessary to maintain skill. Obstetric practice in Australia is similar to that in other developed nations in North America and Europe, so these findings inspire a pessimistic outlook toward any resurgence of enthusiasm for vaginal breech delivery, at least in the near future.

There is no doubt that the Term Breech Trial and its conclusions have been very influential. Critics of that study have highlighted a number of possible flaws in its design, including imprecision and variability in subject selection criteria and labor management practices, as well as access to obstetric, surgical, and neonatal services. ${ }^{4-6,10}$ Indeed, long-term neurodevelopmental outcomes for children presenting as breech at term seem to be the same regardless of the route of delivery. ${ }^{15}$ Several retrospective reviews published since the Term Breech Trial have reported that trials of vaginal breech delivery in carefully selected women, with strict adherence to well-defined intrapartum protocols, can be a safe and reasonable option. ${ }^{16-19}$ However, an obvious and important factor for the success of vaginal breech delivery is that obstetricians are experienced, confident, and enthusiastic about managing labor and delivery in breech presentation.

The current generation of practicing obstetricians is the last to have trained during an era when vaginal breech delivery was not uncommon. This study suggests that the trainee obstetricians who will form the new generation of specialists have little exposure to, and experience in, delivering a breech infant vaginally. Few intend to manage planned trials of vaginal breech delivery once they qualify as specialists. Importantly, although levels of enthusiasm are reported 
to be relatively high at the start of their training, this study found that respondents were less likely to want to manage vaginal breech delivery the more experienced they became. The comments written on many of the survey forms shed light on the possible reasons behind this. Although many respondents expressed the wish to gain more experience in vaginal breech delivery as their training progressed and reported disappointment when this was not achieved, they also described feeling apprehensive about adverse outcomes and their potential medical-legal consequences.

In a situation as potentially complex as vaginal breech delivery, where the skill of the accoucheur is an important factor in the safe conduct of delivery, it seems that trainee exposure and confidence is insufficient to guarantee expertise, meaning that alternative training methods need to be used. Queenan ${ }^{20}$ equates the current status of vaginal breech delivery to that of cardiac arrest, where cardiopulmonary resuscitation training is mandated even though it is an infrequent event, such that when required it can be "performed almost reflexively." He suggests training methods similar to those used for cardiopulmonary resuscitation, such as teaching films, use of mannequins, and regular compulsory instruction, be used for training in vaginal breech delivery for the same reasons. Simulation training in vaginal breech delivery has been shown to be effective in the acquisition of skills for the management of the unplanned vaginal breech delivery, with improved scores in technique and safety. ${ }^{21}$

The results of this survey suggest that calls for a widespread return of planned vaginal breech delivery are likely to fall on deaf ears for the majority of obstetricians-in-training. Glezerman, ${ }^{10}$ in a recent critique of the Term Breech Trial, suggested that the trial's original recommendations were "gratefully accepted" by many Western obstetricians: "It is much easier to plan an abdominal delivery than a vaginal delivery, and it requires less expertise to do so." In light of this study, that situation seems unlikely to change.

\section{REFERENCES}

1. Laws PJ, Sullivan EA. Australia's mothers and babies 2003. AIHW National Perinatal Statistics Unit Sydney. Available at: http:// www.npsu.unsw.edu.au/NPSUweb.nsf/page/ps16. Retrieved July 11, 2007.

2. Gilbert WM, Hicks SM, Boe NM, Danielsen B. Vaginal versus cesarean delivery for breech presentation in California: a population-based study. Obstet Gynecol 2003;102:911-7.

3. Hannah ME, Hannah WJ, Hewson SA, Hodnett ED, Saigal S, Willan AR. Planned caesarean section versus planned vaginal birth for breech presentation at term: a randomized multicentre trial. Lancet 2000;356:1375-83.

4. Kotaska A. Inappropriate use of randomized trials to evaluate complex phenomena: case study of vaginal breech delivery. BMJ 2004;329:1039-42.

5. Hauth JC, Cunningham FG. Vaginal breech delivery is still justified. Obstet Gynecol 2002;99:1115-6.

6. Roosmalen J, Rosendaal F. There is still room for disagreement about vaginal delivery of breech infants at term. BJOG 2002; 109:967-9.

7. Mode of term singleton breech delivery. ACOG Committee Opinion No. 340. American College of Obstetricians and Gynecologists. Obstet Gynecol 2006;108:235-7.

8. The management of breech presentation. Guideline No. 20b. December 2006. Royal College of Obstetricians and Gynaecologists. Available at: www.rcog.org.uk/resources/Public/ pdf/green_top20b_breech.pdf. Retrieved July 11, 2007.

9. College Statement. Breech deliveries at term. C-Obs11. March 2005. The Royal Australian and New Zealand College of Obstetricians and Gynaecologists. Available at: www.ranzcog. edu.au/publications/statements/C-obs11.pdf. Retrieved July $11,2007$.

10. Glezerman M. Five years to the term breech trial: the rise and fall of a randomized controlled trial. Am J Obstet Gynecol 2006;194:20-5.

11. Robson S, Ramsay B, Chandler K. Registrar experience in vaginal breech delivery. How much is occurring? Aust N Z J Obstet Gynaecol 1999;39:215-7.

12. Sharma J, Newman M, Boutchier J, Williams A. National audit of the practice and training in breech deliveries in the United Kingdom. Int J Gynaecol Obstet 1997;59:103-8.

13. Carcopino X, Shojai R, D'Ercole C, Boubli L. French trainees in obstetrics and gynaecology theoretical training and practice of vaginal breech delivery: a national survey. Eur J Obstet Gynecol Reprod Biol 2006. Epub ahead of print.

14. Lavin JP, Eaton J, Hopkins M. Teaching vaginal breech delivery and external cephalic version: a survey of faculty attitudes. J Reprod Med 2000;45:808-12.

15. Whyte H, Hannah ME, Saigal S, Hannah WJ, Hewson S, Amankwah K, et al. Outcomes of children at 2 years after planned cesarean birth versus planned vaginal birth for breech presentation at term: the International Randomized Term Breech Trial. Am J Obstet Gynecol 2004;191:864-71.

16. Doyle NM, Riggs JW, Ramin SM, Sosa MA, Gilstrap LC. Outcomes of term vaginal breech delivery. Am J Perinatol 2005;22:325-8.

17. Alarab M, Regan C, O'Connell MP, Keane DP, O'Herlihy C, Foley ME. Singleton vaginal breech delivery at term: still a safe option. Obstet Gynecol 2004;103:407-12.

18. Giuliani A, Schöll WM, Basver A, Tamussino KF. Mode of delivery and outcome of 699 term singleton breech deliveries at a single center. Am J Obstet Gynecol 2002;187:1694-8.

19. Lashen H, Fear K, Sturdee D. Trends in the management of the breech presentation at term: experience in a District General hospital over a 10-year period. Acta Obstet Gynecol Scand 2002;81:1116-22.

20. Queenan JT. Teaching infrequently used skills: vaginal breech delivery. Obstet Gynecol 2004;103:405-6.

21. Deering S, Brown J, Hodor J, Satin AJ. Simulation training and resident performance of singleton vaginal breech delivery. Obstet Gynecol 2006;107:86-9. 